The Relationships between School Experiences and Mental Health Outcomes among Off-Reserve First Nations Youth

\author{
Anne Guèvremont, Rubab Arim, and Dafna Kohen
}

Statistics Canada

aboriginal policy studies Vol. 5, no. 2, 2016, pp. 60-80

This article can be found at:

http://ejournals.library.ualberta.ca/index.php/aps/article/view/24703

ISSN: 1923-3299

Article DOI: http://dx.doi.org/10.5663/aps.v5i2.24703

aboriginal policy studies is an online, peer-reviewed and multidisciplinary journal that publishes original, scholarly, and policy-relevant research on issues relevant to Métis, non-status Indians and urban Aboriginal people in Canada. For more information, please contact us at apsjournal@ualberta.ca or visit our website at www.nativestudies.ualberta.ca/research/aboriginal-policy-studies-aps.

UNIVERSITY OF ALBERTA

FACULTY OF NATIVE STUDIES 


\section{The Relationships between School Experiences and Mental Health Outcomes among Off-Reserve First Nations Youth}

Anne Guèvremont, Rubab Arim, and Dafna Kohen

Statistics Canada

Abstract: First Nations youth have been shown to have higher rates of mental health problems compared to non-Aboriginal youth. This study used the 2012 Aboriginal Peoples Survey to examine the relationships between school experiences and mental health outcomes for First Nations youth living off reserve. Mental health outcomes included self-rated mental health, psychological distress, the presence of a mood or anxiety disorder, and suicide ideation. This study provides evidence that school factors can offer protective influences as well as pose risks for the mental health of off-reserve First Nations youth. Family assistance with homework, peer influences, school sports participation, and a positive school environment were associated with positive mental health outcomes for off-reserve First Nations youth over and above the associations of mental health with individual and family factors. Findings suggest considering school factors when promoting mental health in First Nations youth.

First Nations youth and young adults have been shown to have higher rates of mental health problems compared to the non-Aboriginal population. In 2001, twelve percent of First Nations adults living off-reserve experienced an episode of major depression, compared to seven percent of all Canadians (Government of Canada 2006). In addition, higher rates of psychological distress have been noted for Aboriginal Canadians compared to nonAboriginal Canadians (twenty-nine percent vs. twenty percent; Caron and Liu 2010). Moreover, higher rates of intentional injuries, including suicide, have been reported for First Nations adults and youth. Between 1989 and 1993, the rate of suicide for First Nations men aged fifteen to twenty-four years was 126 per 100,000, compared to twenty-four per 100,000 for all Canadian men of the same age (Canadian Institute of Child Health 2000). The rate of suicide for young First Nations women was thirty-five per 100,000 versus five per 100,000 for all Canadian women (Canadian Institute of Child Health 2000). Rates of suicide for fifteen-to-twenty-four-year-old Status Indian residents of British Columbia decreased between 1993 and 2010, yet the rates remained significantly higher than the rate for other B.C. residents (3.0 deaths per 10,000 vs. 0.7 deaths per 10,000) (British Columbia Provincial Health Officer 2012).

Mental health outcomes include a number of different but overlapping indicators of individual well-being. Suicide is a particular concern for First Nations youth due to their higher rates of suicide compared to non-Aboriginal youth (Advisory Group on Suicide Prevention 2003; Canadian Institute of Child Health 2000); other mental health outcomes may serve as indicators of and have associations with suicidal thoughts, ideation, and attempts, and are therefore also important to consider. For example, in the general

aboriginal policy studies, vol. 5, no. 2, 2016 
population, self-reported mental health including psychological distress (see the K10 scale developed by Kessler et al. 2002, 2003) has been associated with both depression (Furukawa, Kessler, Slade, and Andrews 2003) and suicidal ideation (Chamberlain, Goldney, Delfabbro, Gill, and Dal Grande 2009).

Self-reported measures are particularly important. They may indicate undiagnosed mental health conditions, but they are also important indicators of quality of life (Mental Health Commission of Canada 2012). Self-rated mental health with a rating of poor, fair, or good (compared to very good or excellent) has been shown to be related to depression, as measured by the World Mental Health-Composite International Diagnostic Interview (WMH-CIDI; Mawani and Gilmour 2010), and self-reported depression is a significant risk factor for suicide (Harder, Rash, Holyk, Jovel, and Harder 2012). Depression has also been associated with low school achievement (Fletcher, 2010; Fröjd et al. 2008) and, later, poor labour market outcomes (Berndt et al. 2000; Ettner, Frank, and Kessler 1997).

The mental health of First Nations youth is complex, with influences at multiple levels including the individual, family, community, and society (Kirmayer et al. 2007). One under-studied area for First Nations youth is the relationship between school experiences and mental health outcomes. Not only do adolescents spend up to a third of their waking hours in school (Rutter, Maughan, Mortimore, and Ouston 1979), but the educational experience of First Nations people is unique and different from the experience of nonAboriginal people. First Nations people may have a particular relationship with the formal educational school system due to the legacy of residential schooling (Aboriginal Healing Foundation 2002). Residential schools were operated across Canada between 1830 and the 1990s, and were largely run by churches in partnership with the federal government (Aboriginal Healing Foundation 2002). Over 100,000 children were removed from their homes, often taken far from their families and communities. While at school, children were prevented from speaking their own languages and learning about their culture and heritage, and many suffered physical and sexual abuse (Aboriginal Healing Foundation 2002). These experiences had and continue to have influences on the mental health of First Nations (Kirmayer et al. 2007).

This paper draws on the ecological framework proposed by Bronfenbrenner (1977), which includes not only the immediate settings of the developing child or youth, but also the larger formal and informal social contexts. In this framework, the environment is conceived of as nested contexts, each contained within the next, with the developing child in the centre. The context most proximal to the child includes the family and the home, followed by the school environment and the peer group. The next level of influence is the broader community or neighbourhood, which exerts an influence, but not as much of an influence as the contexts more proximal to the child. Lastly, the entire framework is encircled by the overarching patterns of culture, including the historical context. In this paper, we focus on a specific part of the proposed ecological framework - that is, school factors, including peers, and their association with youth mental health. 
The Accord on Indigenous Education, created by the Association of Canadian Deans of Education (2010), directed the choice of the factors considered in the present study. The Accord has the vision that "Indigenous identities, cultures, languages, values, ways of knowing, and knowledge systems will flourish in all Canadian learning settings" as a way to contribute to the well-being of Indigenous peoples and their communities (2). The Accord proposes culture and language as fundamental parts of the educational environment, including respectful and welcoming learning environments, respectful and inclusive curricula, culturally responsive pedagogy, and affirming and revitalizing Indigenous languages.

The educational environment, which includes the school climate as well as support for students' language and culture, has been associated with certain youth mental health outcomes (emotional well-being, prosocial behaviour, psychological/nervous disorders). Both positive school climate (e.g. school was a nice place to be, teachers were friendly and fair) and negative school climate (e.g. bullying) have been associated with different mental health outcomes in non-Aboriginal students (Klinger, Mills, and Chapman 2011; Craig and McCuaig Edge 2011). Although fewer published empirical research studies have examined the association between school climate and mental health for Aboriginal students, Kaspar (2013) found that school violence was associated with mental health problems in a study of Canadian Aboriginal youth (Kaspar 2013). Another indicator of the school environment, support for Aboriginal language and culture, may be particularly important for Aboriginal youth. A number of studies have found associations between support for Aboriginal language and culture and positive mental health outcomes for Aboriginal youth (Hallett, Chandler, and Lalonde 2007; Findlay and Kohen 2010).

School environments could also provide opportunities for Indigenous youth to participate in non-academic activities such as sports, arts, or clubs, which have been associated with positive mental health outcomes in studies with non-Aboriginal youth (Bartko and Eccles 2003; Guèvremont, Findlay, and Kohen 2014). Studies with Canadian and American nonAboriginal youth have demonstrated that participation in sports activities is associated with better mental health outcomes (Bartko and Eccles 2003; Guèvremont et al. 2014; Marsh and Kleitman 2003), and participation in non-sport activities has also been shown to have a positive impact on self-esteem and depressed moods (Barber, Eccles, and Stone 2001; Bartko and Eccles 2003; Feldman and Matjasko 2005). To the best of our knowledge, no published empirical research has examined the relationship between non-academic activities and mental health for First Nations youth.

The ecological framework (Bronfenbrenner 1977) theorizes that various contexts surrounding young people contribute to their development, including that of school, as well as family and peers. Family influences are numerous and critically important for youth, but this study focuses specifically on family involvement with school, including parental interactions with the school, such as participation in school activities and events, as well as direct interactions with youth, such as helping with homework. The involvement of family with a young person's school was associated with decreased depression as well as with 
decreased suicidal thoughts in a study of non-Aboriginal youth (Randell, Wang, Herting, and Eggert 2006). However, the relationship between family school involvement and the mental health of First Nations youth is, to the best of our knowledge, understudied. Due to historical influences such as colonization and the legacy of residential schooling, First Nations family members' school experiences may be associated with differential impacts of school involvement rather than the positive effects demonstrated for the non-Aboriginal population. In terms of family influences, socioeconomic factors have been shown to be important for both school characteristics (e.g. school climate, parent school satisfaction; Kohen and Findlay 2014) as well as mental health outcomes (Kirmayer 2007). In terms of peer influence, Kaspar's (2013) study of Canadian Aboriginal youth aged six to fourteen found that those who got along well with their peers were less likely to have mental health disorders (Kaspar 2013). In the present study we consider the influences on youth mental health of school factors, peers, and family through the lens of school involvement and socioeconomic factors.

The ecological framework emphasizes the importance of a variety of contexts that influence children and youth, including school, peers, and family, as well as the influences of larger cultural and historical contexts. These ecological factors have been associated with youth mental health outcomes and have included contexts such as the school environment, school support provided for Aboriginal language and culture, participation in nonacademic activities, peer influences, and family school involvement. These associations have not been comprehensively examined for First Nations youth mental health outcomes.

The impact of residential schooling, as well as the unique cultural perspective of First Nations people, suggest that factors that are associated with mental health outcomes for non-Aboriginal people may differ from those associated with the outcomes for First Nations youth. For example, at the family level, school involvement on the part of parents has been associated with positive school outcomes in the general population (Randell, Wang, Herting, and Eggert 2006). In First Nations families, however, a history of negative school experiences may limit parental involvement (Malatest \& Associates Ltd. 2002) or may be associated with negative school outcomes for First Nations youth.

This study aims to fill the gap and to contribute to the existing research literature by applying elements of the ecological framework (Bronfenbrenner 1977) and of the Accord on Indigenous Education (Association of Canadian Deans of Education 2010), and by using population-based data to examine the relationship between school factors (including family and peers) and mental health outcomes for First Nations youth living off reserve. More specifically, we use the 2012 Aboriginal Peoples Survey (APS) to examine the association of the school environment, family school involvement, and peer influences with four mental health outcomes: self-rated mental health, psychological distress, mood and/or anxiety disorder, and suicide ideation. 


\section{Methods}

\section{Data Source and Sample}

This paper used the 2012 Aboriginal Peoples Survey (APS), a national survey of Aboriginal People aged six and older. The sample for this study $(\mathrm{N}=774)$ was limited to First Nations youth aged fifteen to nineteen living off reserve at the time of the survey. For the 2012 APS, parents of youth aged fifteen to seventeen were given the choice to complete the survey as proxy for their child, or to allow the youth to complete the survey him- or herself. This study includes only the sixty-one percent of youth who completed the survey themselves, because of the personal nature of the mental health questions, and because only the nonproxy sample completed the psychological distress scale. Young people who self-identified as First Nations, either alone or along with another Aboriginal identities, were included in the study.

\section{Measures}

Four self-reporting measures were used to assess mental health: (1) poorer self-rated mental health, (2) higher psychological distress, (3) presence of a mood or anxiety disorder, and (4) ever considered suicide (suicidal ideation). More specific information about these variables, along with the school characteristics considered in this study, are described in Table 1.

\section{Data Analysis}

Data analysis included (a) descriptive statistics for the study variables, (b) correlation analyses for the mental health outcomes to examine their associations, (c) comparison analyses (chi-square for categorical variables and t-tests for continuous variables) to examine differences in the predictor and outcome variables, and (d) logistic regression analyses that included the significant variables based on the statistical comparisons. Due to sample size limitations, a decision rule was applied such that variable inclusion in the logistic regression analysis was based on a significant association with at least one mental health outcome.

\section{Results}

\section{Descriptive Statistics}

Descriptive statistics of the total sample are presented in Table 1. In general, the majority of the respondents reported good mental health, with only a minority reporting mental health problems. These ranged from thirty-nine percent of respondents reporting poorer mental health to fourteen percent reporting ever having considered suicide. 
TABLE 1: Description of Study Measures and Sample Characteristics (N=774)

\begin{tabular}{|c|c|c|}
\hline Variable & Description & $\begin{array}{c}\text { Overall } \\
\text { percentage } \\
\text { or mean } \\
\text { (standard } \\
\text { deviation) } \\
\end{array}$ \\
\hline \multicolumn{3}{|l|}{ Mental Health } \\
\hline $\begin{array}{l}\text { Poorer self- } \\
\text { rated mental } \\
\text { health }\end{array}$ & $\begin{array}{l}\text { Categorized into (0) excellent/very good (better) versus (1) } \\
\text { good/fair/poor (poorer) mental health based on a single item "In } \\
\text { general, would you say your mental health is... excellent? very } \\
\text { good? good? fair? poor?" Categorization was based on sample } \\
\text { size and previous research (Mawani and Gilmour } 2010 \text { ). }\end{array}$ & $39.03 \%$ \\
\hline $\begin{array}{l}\text { Higher } \\
\text { psychological } \\
\text { distress }\end{array}$ & $\begin{array}{l}\text { Categorized into (0) lower versus (1) higher psychological } \\
\text { distress. The } 10 \text {-item Kessler Psychological Distress Scale } \\
\text { (K10) (Kessler et al. 2002, 2003) assesses the frequency of } \\
\text { non-specific psychological distress symptoms (e.g. nervous, } \\
\text { hopeless, sad or depressed) experienced during the previous } \\
\text { month. Each item is rated on a five-point scale ranging from "all } \\
\text { of the time" (5) to "none of the time" (0) (Cronbach's } \\
\text { alpha=0.88). A cut-off score was set based on the } 80^{\text {th }} \\
\text { percentile of scores for First Nations living off-reserve (Bougie, } \\
\text { Arim, Kohen, and Findlay 2015); scores below the cut-off ( } 0-10) \\
\text { were categorized under lower psychological distress, whereas } \\
\text { scores above the cut-off were categorized under higher } \\
\text { psychological distress. More information about the validation of } \\
\text { the K10 scale in the } 2012 \text { APS can be found in Bougie et al. } \\
\text { (2016). }\end{array}$ & $20.99 \%$ \\
\hline $\begin{array}{l}\text { Presence of a } \\
\text { mood or } \\
\text { anxiety } \\
\text { disorder }\end{array}$ & $\begin{array}{l}\text { Categorized into (0) absence versus (1) presence of a mood } \\
\text { (e.g., depression, bipolar disorder, mania or dysthymia) or } \\
\text { anxiety disorder (e.g., phobia, obsessive compulsive disorder, } \\
\text { or panic disorder), based on two separate items that assessed } \\
\text { these long-term conditions that were expected to last or had } \\
\text { already lasted six months or more and had been diagnosed by } \\
\text { a health professional. }\end{array}$ & $19.16 \%$ \\
\hline $\begin{array}{l}\text { Ever } \\
\text { considered } \\
\text { suicide }\end{array}$ & $\begin{array}{l}\text { Categorized into (0) no versus (1) yes, based on a single item: } \\
\text { "Have you ever seriously considered committing suicide or } \\
\text { taking your own life?" }\end{array}$ & $14.36 \%$ \\
\hline \multicolumn{3}{|c|}{ School Aspects } \\
\hline $\begin{array}{l}\text { Positive } \\
\text { school } \\
\text { environment } \\
\text { score }^{b}\end{array}$ & $\begin{array}{l}\text { Based on four items representing positive aspects of the school } \\
\text { environment, such as students feeling safe and happy at } \\
\text { school, most students enjoying being at school, and the school } \\
\text { offering many opportunities for parental involvement; each item } \\
\text { is rated on a four-point scale ranging from (1) strongly disagree } \\
\text { to (4) strongly agree. Range of scale, 1.5-4; Cronbach's } \\
\text { alpha }=.70 \text {. }\end{array}$ & $3.09(0.03)$ \\
\hline $\begin{array}{l}\text { Negative } \\
\text { school } \\
\text { environment } \\
\text { score }^{b}\end{array}$ & $\begin{array}{l}\text { Based on five items representing negative aspects of the school } \\
\text { environment, such as the presence of racism, bullying, alcohol, } \\
\text { drugs, and violence; each item is rated on a four-point scale } \\
\text { ranging from (1) strongly disagree to (4) strongly agree. Range } \\
\text { of scale } 1-4 \text {; Cronbach's alpha=.80. }\end{array}$ & $2.17(0.03)$ \\
\hline
\end{tabular}

${ }^{a}$ These items were subjected to an exploratory factor analysis. The findings indicated that the peer influence construct can be described by two factors, namely, peer educational aspirations (three items) and peer risk behaviours (six items) (see Findlay 2013).

${ }^{b}$ These items were subjected to an exploratory factor analysis. The findings indicated that the school environment construct can be described by two factors, namely, positive (four items) and negative (five items) school environment (see Findlay 2013). 
In terms of the school environment, respondents, on average, perceived their school environment to be more positive (in terms of students enjoying being at school and feeling like the school offered opportunities for parent involvement; mean score of 3.09) than negative (in terms of the presence of racism, bullying, violence, or drugs and alcohol at school; mean scores of 2.17; $\mathrm{t}[761]=31.18, \mathrm{p}<.001$ ). More than a third (thirty-six percent) of the respondents reported participating in weekly school sports activities; over a quarter (twenty-seven percent) participated in arts; and about sixteen percent reported participating in clubs. In terms of language and culture, a third of the respondents (thirty-two percent) indicated that they had been taught an Aboriginal language in classes at school. Almost three-quarters (seventy-four percent) perceived that their school supported First Nations culture.

In terms of family involvement at school, thirty-nine percent of youth reported that their parents were involved in at least two out of three school-related activities (communicated with a teacher, attended a school event, or participated in other school activities). More than half of respondents (fifty-five percent) reported that a parent helped with or checked their homework. Respondents, on average, reported more positive than negative peer influences (mean scores of 3.14 vs $1.70 ; \mathrm{t}[753]=36.82, \mathrm{p}<.001$ ).

The mean age of the respondents was sixteen years. Approximately half of the sample (forty-eight percent) was female. The mean household income, adjusted for household size, was $\$ 37,500$. The majority of the parents (sixty-six percent, both mothers and fathers) had a high school diploma or more.

\section{Correlation Analyses}

As would be expected, there was a moderate statistically significant positive correlation among all mental health outcome variables, with the highest correlation between higher psychological distress and the presence of a mood or anxiety disorder $(\mathrm{r}=0.53, \mathrm{p}<.001)$ and the lowest correlation between ever having considered suicide and poorer self-rated mental health $(\mathrm{r}=0.29, \mathrm{p}<.001)$ (Table 2$)$.

\section{Comparison Analyses}

A summary of the results from the comparison analyses is presented in Table 3. Several factors of the school environment were associated with particular mental health outcomes. Youth with poorer self-rated mental health, those experiencing higher psychological distress, and those who had ever considered suicide had lower scores regarding the positive school environment. As well, youth who had higher psychological distress and who had ever considered suicide had higher scores regarding the negative school environment. Weekly participation in school sports was associated with positive mental health outcomes, with youth who participated in sports experiencing lower rates of psychological distress and of mood or anxiety disorders, and fewer having ever considered suicide. In terms of school support for language and culture, youth who reported that their school supported First Nations culture were less likely to have considered suicide. 
TABLE 2: Correlations among All Mental Health Outcome Variables for Off-Reserve First Nations Youth Currently Attending High School (N=774)

\begin{tabular}{|l|l|c|c|c|c|}
\hline & & $\begin{array}{c}\text { Poorer self- } \\
\text { rated } \\
\text { mental } \\
\text { health }\end{array}$ & $\begin{array}{c}\text { Higher risk } \\
\text { for distress }\end{array}$ & $\begin{array}{c}\text { Presence of a } \\
\text { mood or } \\
\text { anxiety } \\
\text { disorder }\end{array}$ & $\begin{array}{c}\text { Ever } \\
\text { considered } \\
\text { suicide }\end{array}$ \\
\hline 1. & $\begin{array}{l}\text { Poorer self-rated mental } \\
\text { health }\end{array}$ & -- & & & \\
\hline 2. & $\begin{array}{l}\text { Higher psychological } \\
\text { distress }\end{array}$ & $0.43^{* * *}$ & -- & & \\
\hline 3. & $\begin{array}{l}\text { Presence of a mood or } \\
\text { anxiety disorder }\end{array}$ & $0.41^{* * *}$ & $0.53^{* * *}$ & -- & - \\
\hline 4. & Ever considered suicide & $0.29^{* * *}$ & $0.44^{* * *}$ & $0.37^{* * *}$ & - \\
\hline
\end{tabular}

${ }^{* * *} \mathrm{p}<.001$.

Family involvement and peer influence was also associated with off-reserve First Nations youth mental health outcomes in the descriptive analyses. Youth who reported that their families were involved in two or three school activities experienced higher psychological distress less frequently, and scored lower on the presence of a mood or anxiety disorder. As well, youth who said their family helped them with their homework had lower scores for all four mental health outcomes. In terms of peer influence, youth with poorer self-rated mental health had lower scores on positive peer influences and higher scores on negative peer influences. In addition, higher scores on negative peer influences were reported by youth experiencing higher psychological distress, those with a reported mood or anxiety disorder, and those who had considered suicide.

These descriptive analyses identified the predictor variables that differed significantly for at least one of the four outcomes, which were subsequently included in the logistic regression analyses. The following nine variables were retained for the regression models: family involved in school activities; family helping with (or checking) homework; positive peer influences; negative peer influences; positive school environment; negative school environment; participation in sports activities; and school supporting First Nations culture. Together with the four individual and family characteristics (i.e., the young person's age, gender, household income, and parental education), twelve predictor variables were included in the logistic regression models. 


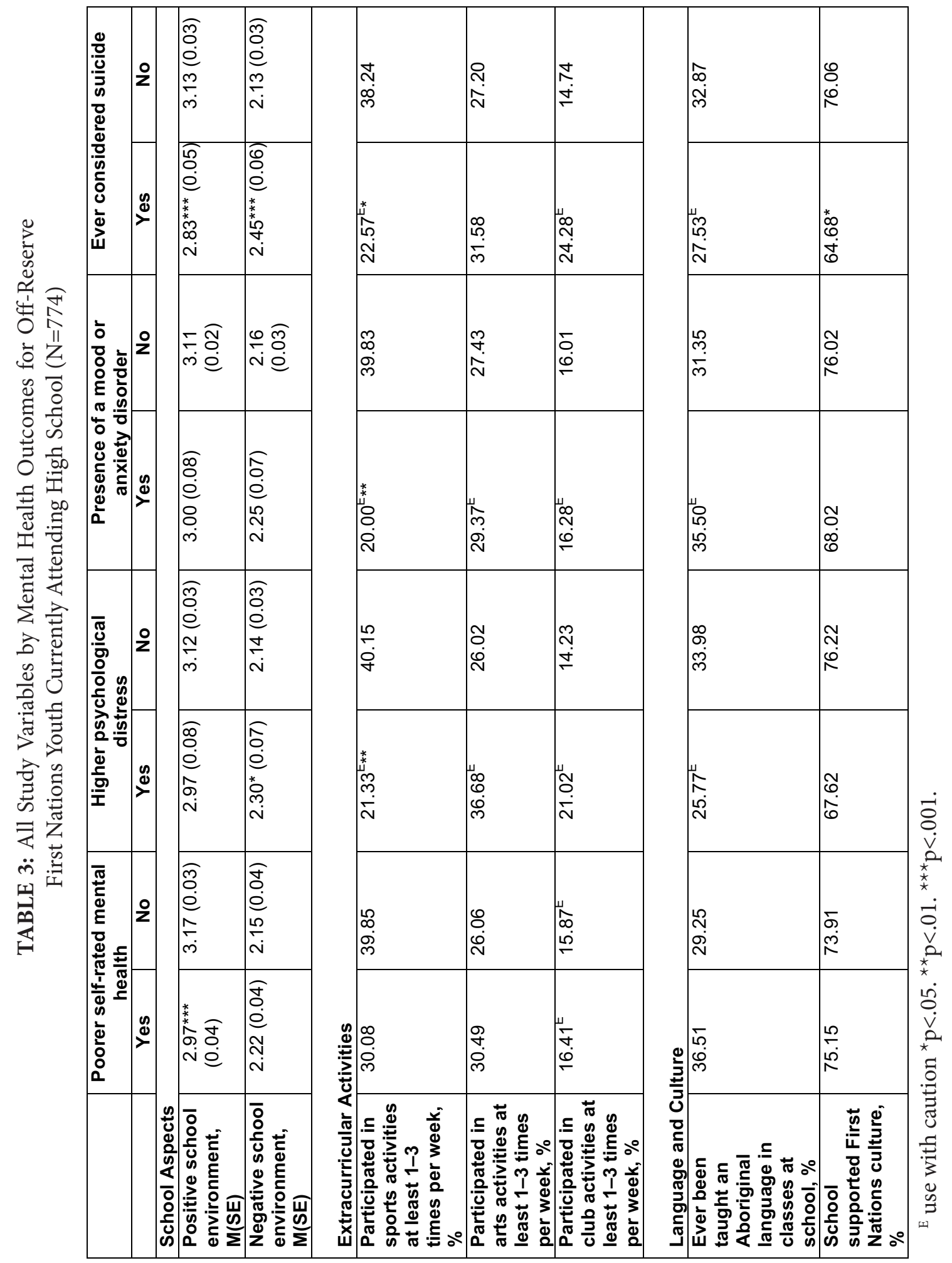




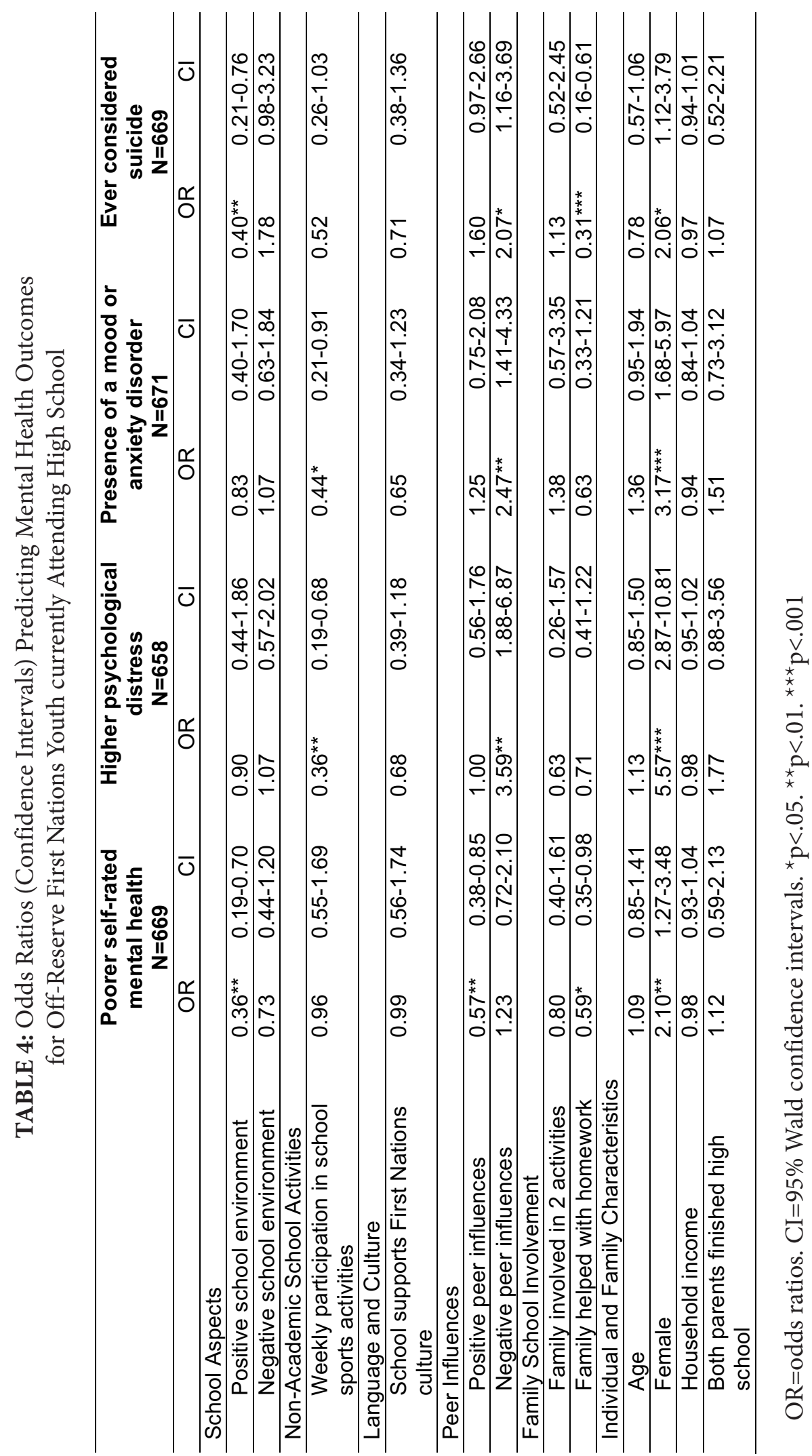




\section{Logistic Regression Analyses}

Table 4 presents a summary of the results from the logistic regression analyses. Only the final models are shown. When looking at all factors simultaneously, one sees that the odds of reporting poorer mental health were higher for those who reported a less-positive school environment, fewer positive peer influences, and less family involvement in school - that is, family not helping with or checking homework. Specifically, the odds of poorer mental health were reduced by more than sixty percent for youth who reported a more positive school environment, by forty percent for youth who reported more positive peer influences, and by forty percent for youth who reported that their family helped with or checked their homework. The odds of reporting poorer mental health were also twice as high for girls as for boys.

The odds of reporting psychological distress were higher for those who reported less participation in sports activities and those who reported more negative peer influences. Specifically, the odds of higher psychological distress were reduced by almost sixty percent for youth who reported participating in sports activities at least one to three times per week. The odds of reporting higher psychological distress were almost four times higher for youth who reported more negative peer influences. The odds of reporting higher psychological distress were also almost six times higher for girls than boys.

The odds of having a mood or anxiety disorder were higher for those who reported less participation in sports activities and more negative peer influences. Specifically, the odds of having a mood or anxiety disorder were reduced by almost sixty percent for youth who reported participating in sports activities at least one to three times per week compared to those who reported less than that. The odds of having a mood or anxiety disorder were almost three times higher for youth who reported more negative peer influences. The odds of having a mood or anxiety disorder were three times higher for girls than boys.

The odds of ever having considered suicide were higher for those who reported a less-positive school environment, more negative peer influences, and family not helping with or checking homework. The odds of ever having considered suicide were reduced by sixty percent for youth who reported a more positive school environment, and by seventy percent for youth who reported that their family helped with or checked their homework. The odds of ever having considered suicide were two times higher for youth who reported more negative peer influences. The odds of ever having considered suicide were twice as high for girls as boys.

\section{Discussion}

This study is one of the few that have used population-based data to examine the association of school factors with mental health outcomes for off-reserve First Nations youth. The majority of off-reserve First Nations youth currently in secondary school reported positive mental health; however, substantial minorities reported poorer self-rated mental health (thirty-nine percent), high psychological distress (twenty-one percent), mood or anxiety 
disorders (nineteen percent), and thoughts of suicide (fourteen percent), and these differed for girls and boys.

Many of the examined factors were associated with positive mental health. More than half of off-reserve First Nations youth reported regular family involvement with homework. Generally, they rated their school environment as more positive than negative, and about one-third participated weekly in school sports activities. In addition, one-third reported that they had been taught an Aboriginal language in school, and three-quarters (seventyfour percent) reported that their school supported Aboriginal culture.

This study found a number of school factors that can exert protective influences on the mental health of off-reserve First Nations youth. A positive school environment, school sports participation, family involvement with school via assistance with homework, and positive peer influences were associated with positive mental health outcomes for offreserve First Nations youth over and above the associations of age, gender, and family income and education. These results suggest that these school factors can be protective for youth mental health regardless of families' levels of income and education.

As suggested by the Accord on Indigenous Education (Association of Canadian Deans of Education 2010), a positive and welcoming school environment is associated with good mental health for off-reserve First Nations youth. Findings from this study support this statement. Youth who reported higher scores regarding a positive school environment (student feels safe and happy at school, most students enjoy being at school, school offers many opportunities for parental involvement) were less likely to experience suicidal ideation and poorer self-rated mental health. This finding is encouraging, particularly because in general, students perceived their school environment to be more positive than negative.

Youth who regularly participated in school sports activities were less likely to report psychological distress or a mood or anxiety disorder, and to have ever considered suicide. These findings are in line with previous literature suggesting that youth sports participation is associated with better mental health outcomes (Eime, Young, Harvey, Charity, and Payne 2013; Fredricks and Eccles, 2006; Sabo, Miller, Melnick, Farrell, and Barnes 2005), but this is among the first studies to find this association for First Nations youth. According to Fredricks and Eccles (2008), extra-curricular activity participation may be associated with positive outcomes as a result of increased 1) opportunities to develop lifelong competencies such as decision-making skills, 2) emotional support from non-parental figures, 3) positive relationships with peers, and 4) identity exploration. However, given that Fredricks and Eccles (2008) focused on the population in general and did not consider Aboriginal youth specifically, future research identifying potential explanatory factors by which sports participation is associated with better mental health for Aboriginal youth is warranted.

Interestingly, the majority (seventy-four percent) of off-reserve First Nations youth reported that their school supported First Nations culture, and approximately one-third of youth reported that they had "ever been taught" an Aboriginal language in classes at school. While the support of First Nations culture was found to be protective against suicide risk, this association was not significant after controlling for socio-demographic 
and school factors, including family involvement with homework, negative peer influence, and positive school environment. The positive effect of a school supporting First Nations culture may thus be manifested through these other school factors.

In terms of family school involvement, infrequent parental involvement in terms of checking or helping with homework was associated with reported suicidal ideation and poorer self-rated mental health. Parental school involvement may reflect how comfortable a parent feels at the school, which could be associated with his or her previous school experiences, including family experience with residential schools (Malatest \& Associates 2002), or whether the parent completed high school (Baker and Stevenson 1986; Balli, Demo, and Wedman 1998; Battiste 1995). Indeed, in the current study, parents who had not completed high school were less likely to help with homework and to have been involved in school activities. Apart from parental level of education and parents' own schooling experiences, parent involvement may also be reflective of the parent-child relationship, which has also been associated with various mental-health outcomes for youth (Repetti, Taylor, and Seeman 2002; Weich, Patterson, Shaw, and Stewart-Brown 2009).

One of the most important influences found across the various mental health outcomes examined was peer influences. Higher scores regarding negative peer influence were associated with higher distress, having a mood or anxiety disorder, and suicidal ideation. In this study, negative peer influence referred to having friends who more frequently skipped classes, dropped out of school, had a reputation for causing trouble, smoked cigarettes, or used drugs and alcohol. Lower scores regarding positive peer influence were associated with having poorer self-rated mental health. The peer scale also assessed peers' educational aspirations. This is consistent with previous research showing that peer influence was associated with mental health outcomes for Aboriginal youth (Kaspar 2013; Mackin et al. 2012).

In terms of individual and family socio-demographic factors, off-reserve First Nations young women were more likely to exhibit mental health problems than were off-reserve First Nations men. This is consistent with the findings of others who have shown higher suicidal ideation in (on-reserve) First Nations female than male youth in Manitoba (Mota et al. 2012). However, research has shown that indigenous males show higher rates of suicide completion than females (Canadian Institute of Child Health 2000), suggesting that males may be less likely to seek help for mental health conditions). Research also suggests that the factors associated with mental health outcomes vary by gender (Kumar et al. 2012). Unfortunately, the sample size in the current study did not allow for an examination of the association between school factors and mental health for male and female youth separately.

\section{Strengths and Limitations}

This study had several strengths. The study used the APS, which is a nationally representative study of off-reserve First Nations people aged six and over. The relatively large sample allowed us to conduct complex analyses of the association between school factors and mental health while controlling for family and individual socio-demographic factors. In addition, this study 
examined multiple school factors, including the school environment, school support for language and culture, participation in extracurricular activities, family school involvement, and peer influences.

Although this study has several strengths, several limitations should be noted. First, while the study included a variable indicating whether the youth's parent or grandparent had attended residential school, broader community variables, which could reflect the historical context, were not included. Chandler and Lalonde (1998) found that youth mental health varies widely among communities, and community characteristics have been shown to be associated with certain outcomes for youth mental health (Kohen, Leventhal, Dahinten, McIntosh 2008). An exploration of how community variables interact with school factors is an area that should be examined. As well, other than family residential school attendance, this study did not include any variables assessing parental school experiences. Examining how parents' school experiences are associated with their school involvement and their children's educational experiences are areas for future research.

The APS did not gather information on all of the school factors that may be associated with positive or negative outcomes for youth mental health. Although we examined aspects of both the negative and positive school environment, several aspects of the school were not examined, such as teacher behavior and involvement, youth school engagement, and youth connectedness to school (Zullig, Koopman, Patton, and Ubbes 2010). Another area for future research is the exploration of the relationship between mental health and school outcomes for First Nations students in longitudinal data that would help determine the direction of influence. As well, further explorations of gender differences and differences in risk and protective factors for male and female youth are important areas for future study.

Since all outcomes in this study were self-reported, future studies should incorporate additional outcome measures. For example, teacher ratings or physician-diagnosed mental health conditions could assess different aspects of mental health outcomes. Also, since all outcomes and predictors were self-reported, it is possible that youth with mental health problems perceive aspects of their school more negatively than young people without such problems. Another limitation is that all variables in this study were collected at one point in time, and all described associations are correlational, so the direction of effects cannot be determined - we cannot tell whether differences in school factors led to better mental health, or whether students with better mental health were more likely to be exposed to and report protective school factors. For example, students with better mental health may surround themselves with and attract more positive peers, and may also be more likely to participate in non-academic school activities. Data collected on the same respondent over time would provide more detail about how school factors influence mental health over time, and allow us to draw conclusions about directionality of effects.

\section{Conclusion}

We found that various school factors were associated with good or poor mental health in off-reserve First Nations youth. A positive school environment, school sports participation, 
family assistance with homework, and positive peer influences were associated with better mental health outcomes for off-reserve First Nations youth over and above the associations of mental health with individual and family factors. Further research involving other mental health outcomes, longitudinal data, additional school factors and family factors, and an examination of gender differences would increase our understanding of the processes involved in the association of school factors with youth mental health outcomes. 


\section{Bibliography}

Aboriginal Healing Foundation. 2002. The Healing Has Begun: An Operational Update from the Aboriginal Healing Foundation. Ottawa: Aboriginal Healing Foundation.

Advisory Group on Suicide Prevention. 2003. Acting on What we Know: Preventing Youth Suicide in First Nations. http://www.hc-sc.gc.ca/fniah-spnia/alt_formats/fnihbdgspni/pdf/pubs/suicide/prev_youth-jeunes-eng.pdf.

Afifi, M. 2007. “Gender Differences in Mental Health." Singapore Medical Journal 485: 38591.

Association of Canadian Deans of Education. 2010. Accord on Indigenous Education. Accessed January 20, 2016. http://www.csse-scee.ca/docs/acde/acde_accord_ indigenousresearch_en.pdf.

Baker, D.P., and D.L. Stevenson. 1986. "Mothers' Strategies for Children's School Achievement: Managing the Transition to High School." Sociology of Education 593: 156-66. doi:10.2307/2112340.

Balli, S.J., D.H. Demo, and J.E. Wedman. 1998. "Family Involvement with Children's Homework: An Intervention in the Middle Grades." Family Relations 471: 149-57. doi: $10.2307 / 585619$.

Barber, B.L., J.S. Eccles, and M.R. Stone. 2001. "Whatever Happened to the Jock, the Brain, and the Princess? Young Adult Pathways Linked to Adolescent Activity Involvement and Social Identity." Journal of Adolescent Research 16: 429-55. doi:10.1177/0743558401165002.

Bartko, W., and J. Eccles. 2003. "Adolescent Participation in Structured and Unstructured Activities: A Person-Oriented Analysis." Journal of Youth and Adolescence 324: 23341. doi:10.1023/a:1023056425648.

Berndt, E.R., L.M. Koran, S.N. Finkelstein, A.J. Gelenberg, S.G. Kornsteig, I.M. Miller ... and M.B. Keller. 2000. "Lost Human Capital from Early-Onset Chronic Depression." American Journal of Psychiatry 157(6): 940-47. doi:10.1176/appi.ajp.157.6.940.

Bougie, E., R.G. Arim, D.E. Kohen, and L.C. Findlay. 2016. "Validation of the 10-Item Kessler Psychological Distress Scale (K10) in the 2012 Aboriginal Peoples Survey." Health Reports 27: 3-10. 
British Columbia Provincial Health Officer. 2012. The Health and Well-Being of the Aboriginal Population. Victoria, BC. Office of the Provincial Health Officer.

Bronfenbrenner, U. 1977. "Toward an Experimental Ecology of Human Development." American Psychologist 32: 513-31. doi:10.1037/0003-066x.32.7.513.

Canadian Institute of Child Health. 2000. The Health of Canada's Children: A CICH Profile. Third ed. http://www.cich.ca/PDFFiles/Profile/CICH\%20Profile_06\%20 Aboriginal.pdf.

Caron, J., and A. Liu. 2010. "A Descriptive Study of the Prevalence of Psychological Distress and Mental Disorders in the Canadian Population: Comparison between LowIncome and Non-Low-Income Populations." Chronic Diseases in Canada 303: 8494. http://publications.gc.ca/collections/collection_2010/aspc-phac/H12-27-30-3eng.pdf.

Chamberlain, P., R. Goldney, P. Delfabbro, T. Gill, and L. Dal Grande. 2009. "Suicide Ideation: The Clinical Utility of the K10." Crisis 301: 39-42. doi:10.1027/02275910.30.1.39.

Chandler, M., and C. Lalonde. 1998. "Cultural Continuity as a Hedge against Suicide in Canada's First Nations." Transcultural Psychiatry 35: 191-219. doi:10.1177/136346159803500202.

Craig, W., and H. McCuaig Edge. 2011. "Bullying and Fighting." In The Health of Canada's Young People: A Mental Health Focus, edited by J.G. Freeman, M. King, and M.W. Pickett, with W. Craig, F. Elgar, F. I. Janssen, and D. Klinger, 167-83. Public Health Agency of Canada Catalogue No. HP15-13/2011E. http://www.phac-aspc.gc.ca/hpps/dca-dea/publications/hbsc-mental-mentale/assets/pdf/hbsc-mental-mentaleeng.pdf.

Eime, R.M., J.A. Young, J.T. Harvey, M.J. Charity, and W.R. Payne. 2013. "A Systematic Review of the Psychological and Social Benefits of Participation in Sport for Children and Adolescents: Informing Development of a Conceptual Model of Health through Sport." International Journal of Behavioral Nutrition and Physical Activity 1098: 1-21. doi:10.1186/1479-5868-10-98 http://www.ncbi.nlm.nih.gov/ pmc/articles/PMC3751802/pdf/1479-5868-10-98.pdf.

Ettner, S., F. Frank, and R. Kessler. 1997. “The Impact of Psychiatric Disorders on Labor Market Outcomes." Industrial and Labor Relations Review 51(1): 64-81. doi:10.2307/2525035. 
Feldman, A.F., and J.L. Matjasko. 2005. "The Role of School-Based Extracurricular Activities in Adolescent Development: A Comprehensive Review and Future Directions." Review of Educational Research 752: 159-210. doi:10.3102/00346543075002159.

Findlay, L.C. 2013. "APS Exploratory Analysis on School Climate and Peer Influence Items." Unpublished manuscript.

Findlay, L.C., and D.E. Kohen. 2010. “Child Care for First Nations Children Living off Reserve, Métis Children, and Inuit Children." Canadian Social Trends 90, 83-91. Statistics Canada Catalogue no. 11-008-X. http://www.statcan.gc.ca/pub/11008-x/2010002/article/11344-eng.pdf.

Fletcher, J.M. 2010. "Adolescent Depression and Educational Attainment: Evidence from Sibling Fixed Effects." Health Economics 197: 855-71. doi:10.1002/hec.1526.

Fredricks, J.A., and Eccles, J. S. 2008. "Participation in Extracurricular Activities in the Middle School Years: Are There Developmental Benefits for African American and European American Youth?" Journal of Youth and Adolescence 37(9): 1029-43. doi:10.1007/s10964-008-9309-4.

- - - 2006. "Is Extracurricular Participation Associated with Beneficial Outcomes? Concurrent and Longitudinal Relations." Developmental Psychology 424: 698-713. doi:10.1037/0012-1649.42.4.698.

Fröjd, S.A., E.S. Nissinen, M.U. Pelkonen, M.J. Marttunen, A.M. Koivisto, and R. KaltialaHeino. 2008. "Depression and School Performance in Middle Adolescent Boys and Girls." Journal of Adolescence 314: 485-98. doi:10.1016/j.adolescence.2007.08.006.

Furukawa, T.A., R.C. Kessler, T. Slade, and G. Andrews. 2003. “The Performance of the K6 and K10 Screening Scales for Psychological Distress in the Australian National Survey of Mental Health and Well-Being." Psychological Medicine 33, 357-62. doi:10.1017/S0033291702006700.

Government of Canada. 2006. The Human Face of Mental Health and Mental Illness in Canada. Minister of Public Works and Government Services Canada Catalogue. No. HP5-19/2006E. http://www.phac-aspc.gc.ca/publicat/human-humain06/pdf/ human_face_e.pdf.

Guèvremont, A., L. Findlay, and D. Kohen. 2014. "Organized Extracurricular Activities: Are In-School and Out-of-School Activities Associated with Different Outcomes for Canadian Youth?" Journal of School Health 84, 317-25. doi:10.1111/josh.12154. 
Hallett, D., M.J. Chandler, and C.E. Lalonde. 2007. "Aboriginal Language Knowledge and Youth Suicide." Cognitive Development22,392-99.doi:10.1016/j.cogdev.2007.02.001.

Harder, H.G., J. Rash, T. Holyk, E. Jovel, and K. Harder. 2012. "Indigenous Youth Suicide: A Systematic Review of the Literature." Pimatisiwin: Journal of Aboriginal Indigenous Community Health 10: 125-42. http://www.pimatisiwin.com/online/wp-content/ uploads/2012/07/10HarderNew.pdf.

Kaspar, V. 2013. "Mental Health of Aboriginal Children and Adolescents in Violent School Environments: Protective Mediators of Violence and Psychological/ Nervous Disorders." Social Science and Medicine 81: 70-8. doi:10.1016/j. socscimed.2012.12.011.

Kessler, R.C., G. Andrews, L.J. Colpe, E. Hiripi, D.K. Mroczek, S.L.T. Normand ... and A.M. Zaslavsky. 2002. "Short Screening Scales to Monitor Population Prevalences and Trends in Non-Specific Psychological Distress.” Psychological Medicine 32: 959-76. doi:10.1017/S0033291702006074.

Kessler, R.C., P.R. Barker, L.J. Colpe, J.F. Epstein, J.C Gfroerer, E. Hiripi ... and A.M. Zaslavsky. 2003. "Screening for Serious Mental Illness in the General Population." Archives of General Psychiatry 60, 184-89. doi:10.1001/archpsyc.60.2.184.

Kirmayer, L.J., G.M. Brass, T. Holton, K. Paul, C. Simpson, and C. Tait. 2007. Suicide among Aboriginal People in Canada. Ottawa, ON: Aboriginal Healing Foundation.

Klinger, D., A. Mills, and C. Chapman. 2011. "School." In Freeman et al., The Health of Canada's Young People, 47-65. Public Health Agency of Canada Catalogue No. HP15-13/2011E. http://www.phac-aspc.gc.ca/hp-ps/dca-dea/publications/hbscmental-mentale/assets/pdf/hbsc-mental-mentale-eng.pdf.

Kohen, D., T. Leventhal, S. Dahinten, and C. McIntosh. 2008. "Neighborhood Disadvantage: Pathways of Effects for Young Children.” Child Development 79(1): 156-69. doi:10.1111/j.1467-8624.2007.01117.x.

Kohen, D., and L. Findlay. 2014. "Neighbourhood Effects and Young Children's Outcomes.” In Wellbeing: A Complete Reference Guide, Volume I, Wellbeing in Children and Families, edited by S.H. Landry and C.L. Cooper, 1-23. Hoboken, NJ: John Wiley and Sons. doi:10.1002/9781118539415.wbwell016. 
Kumar, M.B., M. Walls, T. Janz, P. Hutchinson, T. Turner, and C. Graham. 2012. "Suicidal Ideation among Métis Adult Men and Women - Associated Risk and Protective Factors: Findings from a Nationally Representative Survey." International Journal of Circumpolar Health 71. doi:10.3402/ijch.v71i0.18829.

Mackin, J., T. Perkins, and C. Furrer. 2012. “The Power of Protection: A Population-Based Comparison of Native and Non-Native Youth Suicide Attempters." American Indian and Alaska Native Mental Health Research: The Journal of the National Center 19(2): 20-54. doi:10.5820/aian.1902.2012.20.

Malatest \& Associates Ltd. 2002. "Parent and Education Engagement Partnership Project: A Discussion Paper." B.C. Ministry of Education.

Marsh, H.W., and S. Kleitman. 2003. "School Athletic Participation: Mostly Gain with Little Pain." Journal of Sport and Exercise Psychology 25: 205-28.

Mawani, F.N., and H. Gilmour. 2010. "Validation of Self-Rated Mental Health." Health Reports 213: 61-75. Statistics Canada Catalogue no. 82-003-XPE. http://www. statcan.gc.ca/pub/82-003-x/2010003/article/11288-eng.pdf.

Mental Health Commission of Canada. 2012. Changing Directions, Changing Lives: The Mental Health Strategy for Canada. http://strategy.mentalhealthcommission.ca/ pdf/strategy-text-en.pdf.

Mota, N., B. Elias, B. Tefft, M. Medved, G. Munro, and J. Sareen. 2012. "Correlates of Suicidality: Investigation of a Representative Sample of Manitoba First Nations Adolescents." American Journal of Public Health 102(7): 1353-61. doi:10.2105/ ajph.2011.300385.

Randell, B.P., W.L. Wang, J.R. Herting, and L.L. Eggert. 2006. "Family Factors Predicting Categories of Suicide Risk." Journal of Child and Family Studies 153: 247-62. doi:10.1007/s10826-006-9020-6.

Repetti, R., S. Taylor, and T. Seeman. 2002. "Risky Families: Family Social Environments and the Mental and Physical Health of Offspring." Psychological Bulletin 128, 33066. doi:10.1037//0033-2909.128.2.330.

Rutter, M., B. Maughan, P. Mortimore, and J. Ouston. 1979. Fifteen Thousand Hours: Secondary Schools and their Effects on Children. London, UK: Open Books. 
Sabo, D., K.E. Miller, M.J. Melnick, M.P. Farrell, and G.M. Barnes. 2005. "High School Athletic Participation and Adolescent Suicide." International Review for the Sociology of Sport 401: 5-23. doi:10.1177/1012690205052160.

Weich, S., J. Patterson, R. Shaw, and S. Stewart-Brown. 2009. "Family Relationships in Childhood and Common Psychiatric Disorders in Later Life: Systematic Review of Prospective Studies. British Journal of Psychiatry 194: 392-98. doi:10.1192/bjp. bp.107.042515.

Zullig, K.J., T.M. Koopman, J.M. Patton, and V.A. Ubbes. 2010. "School Climate: Historical Review, Instrument Development, and School Assessment." Journal of Psychoeducational Assessment 28: 139-52. doi:10.1002/pi. 